Atmos. Chem. Phys., 19, 13759-13771, 2019

https://doi.org/10.5194/acp-19-13759-2019

(C) Author(s) 2019. This work is distributed under

the Creative Commons Attribution 4.0 License.

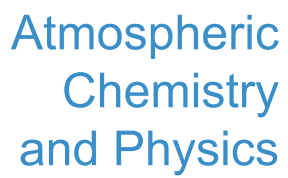

(c) (P)

\title{
Possible implications of enhanced chlorofluorocarbon-11 concentrations on ozone
}

\author{
Martin Dameris, Patrick Jöckel, and Matthias Nützel \\ Deutsches Zentrum für Luft- und Raumfahrt, Institut für Physik der Atmosphäre, Oberpfaffenhofen, Germany
}

Correspondence: Martin Dameris (martin.dameris@dlr.de)

Received: 12 March 2019 - Discussion started: 18 March 2019

Revised: 9 October 2019 - Accepted: 11 October 2019 - Published: 15 November 2019

\begin{abstract}
This numerical model study is motivated by the observed global deviation from assumed emissions of chlorofluorocarbon-11 (CFC-11, $\left.\mathrm{CFCl}_{3}\right)$ in recent years. Montzka et al. (2018) discussed a strong deviation of the assumed emissions of CFC-11 over the past 15 years, which indicates a violation of the Montreal Protocol for the protection of the ozone layer. An investigation is performed which is based on chemistry-climate model (CCM) simulations that analyze the consequences of an enhanced CFC-11 surface mixing ratio. In comparison to a reference simulation (REF$\mathrm{C} 2$ ), where a decrease of the CFC-11 surface mixing ratio of about $50 \%$ is assumed from the early 2000 s to the middle of the century (i.e., a mixing ratio in full compliance with the Montreal Protocol agreement), two sensitivity simulations are carried out. In the first simulation the CFC-11 surface mixing ratio is kept constant after the year 2002 until 2050 (SEN-C2-fCFC11_2050); this allows a qualitative estimate of possible consequences of a high-level stable CFC11 surface mixing ratio on the ozone layer. In the second sensitivity simulation, which is branched off from the first sensitivity simulation, it is assumed that the Montreal Protocol is fully implemented again starting in the year 2020, which leads to a delayed decrease of CFC- 11 in this simulation (SEN-C2-fCFC11_2020) compared with the reference simulation; this enables a rough and most likely upperlimit assessment of how much the unexpected CFC-11 emissions to date have already affected ozone. In all three simulations, the climate evolves under the same greenhouse gas scenario (i.e., RCP6.0) and all other ozone-depleting substances decline (according to this scenario). Differences between the reference (REF-C2) and the two sensitivity simulations (SEN-C2-fCFC11_2050 and SEN-C2-fCFC11_2020) are discussed. In the SEN-C2-fCFC11_2050 simulation, the
\end{abstract}

total column ozone (TCO) in the 2040s (i.e., the years 20412050) is particularly affected in both polar regions in winter and spring. Maximum discrepancies in the TCO values are identified with reduced ozone values of up to around 30 Dobson units in the Southern Hemisphere (SH) polar region during SH spring (in the order of $15 \%$ ). An analysis of the respective partial column ozone (PCO) for the stratosphere indicates that the strongest ozone changes are calculated for the polar lower stratosphere, where they are mainly driven by the enhanced stratospheric chlorine content and associated heterogeneous chemical processes. Furthermore, it was found that the calculated ozone changes, especially in the upper stratosphere, are surprisingly small. For the first time in such a scenario, we perform a complete ozone budget analysis regarding the production and loss cycles. In the upper stratosphere, the budget analysis shows that the additional ozone depletion due to the catalysis by reactive chlorine is partly compensated for by other processes related to enhanced ozone production or reduced ozone loss, for instance from nitrous oxide $\left(\mathrm{NO}_{x}\right)$. Based on the analysis of the SEN-C2-fCFC11_2020 simulation, it was found that no major ozone changes can be expected after the year 2050, and that these changes are related to the enhanced CFC-11 emissions in recent years.

\section{Introduction}

The estimation of the future evolution of the ozone layer is a central part of the UNEP/WMO Scientific Assessment of Ozone Depletion. For this reason, chemistry-climate models (CCM) are employed to carry out long-term simulations (for several decades). These models are used to perform compre- 
hensive numerical simulations under well-defined boundary conditions that prescribe possible future changes of ozonedepleting substances (ODSs), particularly those related to changes in chlorofluorocarbon (CFC) concentrations. In recent years, model guidelines have been defined to facilitate the intercomparison of CCM results from different modeling groups worldwide. For instance, in 2012, the ChemistryClimate Model Initiative (CCMI), under the umbrella of IGAC/SPARC, defined the boundary conditions for the next round of coordinated reference (REF) and sensitivity (SEN) simulations (Eyring et al., 2013). The boundary conditions for the CCM simulations consider not only the expected changes in ODSs according to the regulations of the Montreal Protocol and its amendments, but also the influence of different climate change scenarios. Here, the greenhouse gas concentrations for the Representative Concentration Pathways (RCPs) adopted by the IPCC for its Fifth Assessment Report (AR5) in 2014 (van Vuuren et al., 2011) were recommended. The suggested reference simulation for the future (REF-C2) assumes full compliance with the Montreal Protocol, expecting more or less no further production of CFCs.

More recently the respective CCM results have been presented and discussed in several scientific papers, for instance Dhomse et al. (2018). Among other topics, the question of ozone recovery has been investigated, including how the speed of recovery and the return date of ozone are affected by the expected decrease in ODSs and by climate change. The results of the CCM simulations were taken into account as the foundation for the latest WMO ozone report (WMO, 2018).

During the preparation phase of WMO (2018) a paper by Montzka et al. (2018) was published (hereafter referred to as M18), which indicated a clear deviation of the expected surface concentration of chlorofluorocarbon-11 (CFC-11, $\mathrm{CFCl}_{3}$ ) during the past 15 years. Observational datasets discussed by M18 showed the following: (1) in the last 10 years (until 2017) the decline of CFC-11 surface mixing ratios has been much slower than expected (see Fig. 1a in M18); and (2) the decline of CFC-11 surface mixing ratios was nearly constant from 2002 to 2012, whereas in the following years the decrease of CFC-11 surface mixing ratios decelerated (here until 2017; see Fig. 1b in M18). The measurements indicated increased CFC-11 emissions after 2012 (see Fig. 2a in M18; see also Figure ES-2 in WMO, 2018). M18 proposed that these observations imply "a gap in our understanding of CFC-11 sources and sinks since the early 2000s".

Based on these findings a significant impact on the recovery of the ozone layer seems to be possible, in particular, if CFC-11 emissions do not decline as previously anticipated (e.g., Daniel et al., 2011; Carpenter et al., 2014). Therefore, the assumption of a decreasing CFC-11 surface mixing ratio in the future by CCMI is somewhat questionable. Currently, the future evolution of CFC-11 emissions is uncertain (Harris et al., 2019). Therefore, for this numerical study, we cannot decide which future scenario is most likely; the pos-

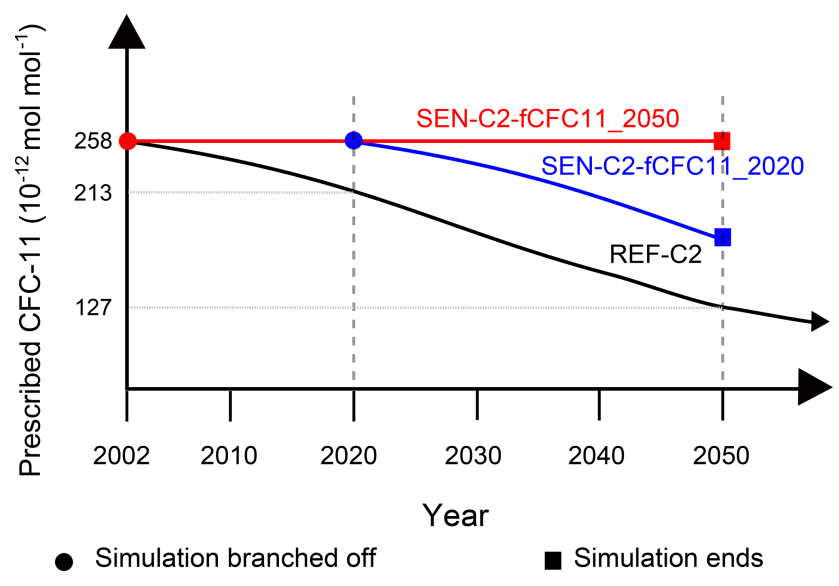

Figure 1. Schematic of the EMAC model simulations performed: a reference simulation (REF-C2) and two sensitivity simulations (SEN-C2-fCFC11_2020 and SEN-C2-fCFC11_2050) enabling an assessment of enhanced CFC-11 surface mixing ratios on the ozone layer. The prescribed CFC-11 surface mixing ratios are given on the nonlinear vertical axis. The prescribed CFC-11 surface mixing ratios are based on Table 5A-3 in Daniel et al. (2011).

sible ranges of future CFC-11 emission changes are also difficult to estimate. Our approach is to employ a high-emission scenario of CFC-11 in a sensitivity simulation (SEN-C2fCFC11_2050) by imposing constant surface mixing ratios of CFC-11 from 2002 onwards (Fig. 1). The sensitivity simulation covers the period from 2002 to 2050 . This sensitivity simulation should not be considered as a specific future scenario that we deem likely. As previously stated, this model setup can be viewed as a high-level scenario regarding CFC-11 background conditions. The reason for starting this sensitivity simulation in the year 2002 is motivated by the findings of M18, who showed that the observed emissions started to diverge from the expected emissions of CFC11 from 2002 onward (e.g., Fig. 2a in M18). We note that stable CFC-11 emissions are not equal to stable CFC-11 surface concentrations; however, due to the fact that the future evolution of CFC-11 emissions (and also the surface mixing ratio) is uncertain, such a simplified (crude) assumption of a constant surface mixing ratio is absolutely justified as a high-level scenario dating back to the point when expected emissions and observations started to diverge. An alternative sensitivity simulation could be created assuming a later starting date (e.g., 2017) with a constant surface mixing ratio on a lower level, i.e., prescribing a lower surface mixing ratio. We expect that the results of such a sensitivity simulation after $\sim 50$ years of simulation (e.g., 2065 for a start in 2017) would only change slightly in a quantitative manner compared with our SEN-C2-fCFC11_2050 (in 2050), but not qualitatively compared with the reference simulation. Based on our understanding, the calculated ozone changes are primarily affected by the prescribed CFC-11 differences (e.g., 
between REF-C2 and SEN-C2-fCFC11_2050) rather than by the CFC-11 background value.

Although M18 hinted that the additional CFC-11 emissions might be released in eastern Asia (see also Rigby et al., 2019), we do not impose any specific regional features due to the long lifetime of CFC-11 (e.g., Rigby et al., 2013). In comparison with the reference simulation (REF-C2), the SENC2-fCFC11_2050 sensitivity simulation allows us to investigate the potential impact of previously unaccounted for CFC11 emissions. It enables a rough estimation of the additional possible ozone loss under a constant CFC-11 surface mixing ratio in the coming years and how it may impact the timing of the full recovery of the ozone layer. In addition, the second sensitivity simulation (SEN-C2-fCFC11_2020, see also Fig. 1) is carried out to allow for an estimate of ozone changes in case of full recognition and implementation of the Montreal Protocol again in the coming years. After an 18-year period with a constant CFC-11 surface mixing ratio (in line with SEN-C2-fCFC11_2050 from 2002 to 2019), the CFC-11 surface mixing ratio is decreased in the following years (in parallel with REF-C2) under the assumption that the recent additional CFC-11 emissions will drop down to zero starting in the year 2020 .

It is the aim of this study to show when and where ozone loss occurs due to the additional influx of CFC-11 into the atmosphere while other ODSs decline as expected. Our scenario, described in SEN-C2-fCFC11_2050, could be taken as "what should be avoided", somewhat in the tradition of the Newman et al. (2009) paper. Furthermore, SEN-C2fCFC11_2020 provides an estimate of the impact of the temporary increase in CFC-11 emissions in recent years on the ozone layer and its recovery. Our analysis presented here does not aim at specifically investigating the effects of the discovered CFC-11 emissions and numerous "directly" related scenarios. Instead, we want to assess the impact of an enhanced CFC-11 surface mixing ratio as a sensitivity study. The foundation for our numerical exercise is the REF-C2 simulation, which was performed with our CCM EMAC (see description in Sect. 2). The results of this reference simulation were one of our several contributions to the Dhomse et al. (2018) study and WMO (2018). The results of EMAC were checked against observations (for the past) in detail (e.g., Jöckel et al., 2016) and were also compared with results derived from other CCMs. No obvious weaknesses or significant deficiencies could be identified.

After a short description of the CCM used and the model simulations analyzed (REF-C2, SEN-C2-fCFC11_2050, and SEN-C2-fCFC11_2020) in the next section (Sect. 2), the CCM results are presented in Sect. 3. With respect to the results, we focus on changes in total column ozone and partial stratospheric columns in specific geographical regions and seasons. To the best of our knowledge, a detailed ozone budget analysis for such sensitivity simulations is performed and presented for the first time. Finally, the discussion and conclusion are presented at the end of this paper.

\section{Description of the model and simulations}

In this study, version 2.52 of the CCM EMAC, which stands for "European Centre for Medium-Range Weather Forecasts - Hamburg (ECHAM)/Modular Earth Submodel System (MESSy) Atmospheric Chemistry model", is used and is operated in T42L90MA resolution, corresponding to a quadratic Gaussian grid of approx. $2.8^{\circ} \times 2.8^{\circ}$ in latitude and longitude with 90 levels up to $0.01 \mathrm{hPa}$. More details are given in Jöckel et al. (2016).

The joint IGAC/SPARC Chemistry-Climate Model Initiative (CCMI) proposed several reference and sensitivity simulations for CCM studies. The aim was to support upcoming ozone and climate assessment reports. From this connection, an internally consistent simulation from the past into the future between 1960 and 2100 has been suggested (Eyring et al., 2013). This transient reference simulation, i.e., REF-C2, as used in this study, is forced by trace gas projections as well as prescribed sea surface temperatures (SSTs) and sea ice concentrations (SICs). The projection component of REF-C2 uses greenhouse gas concentrations (i.e., $\mathrm{CO}_{2}, \mathrm{CH}_{4}$, and $\mathrm{N}_{2} \mathrm{O}$ ) that follow the Intergovernmental Panel on Climate Change (IPCC) Coupled Model Intercomparison Project Phase 5 (CMIP5) Representative Concentration Pathways 6.0 (RCP6.0) scenario (van Vuuren et al., 2011). Monthly mean global SST and SIC data, which were simulated by the HadGEM2 climate model with an interactive ocean (Hadley Centre Global Environmental Model version 2, data used for the RCP6.0 scenario; see Jones et al., 2011), were used as boundary conditions for the REF-C2 simulation.

For this study, in addition to the REF-C2 simulation (for more details see Jöckel et al., 2016; here it is the "RC2-base04" reference simulation), two specific sensitivity simulations (SEN-C2-fCFC11_2050 and SEN-C2-fCFC11_2020) are designed to address the possible consequences of additional emissions of CFC-11, which affect the chlorine content of the stratosphere after a period of years. In all EMAC simulations mixing ratios of ODSs (CFCs: $\mathrm{CFCl}_{3}, \mathrm{CF}_{2} \mathrm{Cl}_{2}$, $\mathrm{CH}_{3} \mathrm{CCl}_{3}$, and $\mathrm{CCl}_{4}$; HCFCs: $\mathrm{CH}_{3} \mathrm{Cl}$ and $\mathrm{CH}_{3} \mathrm{Br}$; Halons: $\mathrm{CF}_{2} \mathrm{ClBr}$ and $\mathrm{CF}_{3} \mathrm{Br}$ ) in the lowest model layer are adapted by Newtonian relaxation to observed or projected surface mixing ratios (Kerkweg et al., 2006). The applied tracer nudging procedure diagnoses the emission flux of CFC-11, which is necessary to adjust to the prescribed surface mixing ratio. In the REF-C2 simulation, the mean $\mathrm{CFC}-11$ surface mixing ratio in the year 2002 is $258.3 \times 10^{-12} \mathrm{~mol} \mathrm{~mol}^{-1}$ (see Table 5A-3 in Daniel et al., 2011), and it is significantly reduced by more than $50 \%\left(127.2 \times 10^{-12} \mathrm{~mol} \mathrm{~mol}^{-1}\right)$ in the year 2050 (i.e., the mixing ratio of the baseline (A1) scenario; WMO, 2011; the respective values are also presented in Fig. 1). The 2050 value is projected under the assumption of full compliance with the Montreal Protocol. The cumulative CFC-11 emissions in the REF-C2 simulation (from 2002 to 2050) result in about $400 \mathrm{Gg}$. Apart from one point, 
the sensitivity simulation (SEN-C2-fCFC11_2050) is identical to the reference simulation (REF-C2): in the sensitivity simulation the $\mathrm{CFC}-11$ mean surface mixing ratio is kept constant at $258.3 \times 10^{-12} \mathrm{~mol} \mathrm{~mol}^{-1}$ after the year 2002 , whereas in REF-C2 it declines. The CFC-11 emissions required to achieve the constant surface mixing ratio value in our model after the year 2002 in SEN-C2-fCFC11_2050 is about $90 \mathrm{Gg} \mathrm{yr}^{-1}$ (e.g., for the year 2003 it is $87 \mathrm{Gg} \mathrm{yr}^{-1}$; the emissions in our model simulation increase slightly with time, which is likely due to the small reduction in the CFC11 lifetime; see for instance SPARC, 2013). The cumulative CFC-11 emissions (from 2002 to 2050) result in about $4500 \mathrm{Gg}$ (i.e., roughly $4100 \mathrm{Gg}$ more than in REF-C2). The emission values derived from observations given by Montzka et al. (2018) are about $65 \mathrm{Gg} \mathrm{yr}^{-1}$ (mean) for 2002 to 2012 and $75 \mathrm{Gg} \mathrm{yr}^{-1}$ from 2014 to 2016 (see also Rigby et al., 2019). The figures presented by Rigby et al. (2019) and Harris et al. (2019) with respect to the temporal evolution of CFC-11 emissions indicated a further increase after 2016. In the second sensitivity simulation, SEN-C2-fCFC11_2020, full adherence of the Montreal Protocol is assumed after the year 2020. The starting point of this simulation is aligned with SEN-C2-fCFC11_2050, assuming the same constant CFC-11 surface mixing ratio between 2002 and 2019 (i.e., $258.3 \times 10^{-12} \mathrm{~mol} \mathrm{~mol}^{-1}$ ), but with decreasing mixing ratios after 2020 until 2050. The cumulative CFC-11 emissions (from 2002 to 2050) result in about $2100 \mathrm{Gg}$ (i.e., roughly $1700 \mathrm{Gg}$ more than in REF-C2). A schematic of our three model simulations is presented in Fig. 1.

In both sensitivity simulations, we do not emphasize specific regions regarding outstanding changes of the CFC-11 surface mixing ratio, e.g., in eastern Asia (see discussion in Sect. 1). The modified CFC-11 boundary condition in the SEN-C2-fCFC11_2050 and SEN-C2-fCFC11_2020 simulations should cause a change of the stratospheric chlorine loading after about 10-15 years (e.g., Engel et al., 2002).

\section{Presentation of CCM results}

\subsection{Reactive chlorine}

Based on the prescribed changes of the CFC-11 boundary conditions the stratospheric content of reactive chlorine compounds $\left(\mathrm{ClO}_{x}=\mathrm{Cl}+\mathrm{ClO}+\mathrm{OClO}+2 \mathrm{ClOOCl}+2 \mathrm{Cl}_{2}+\mathrm{HOCl}\right)$ is expected to change. In Fig. 2, the simulated change (i.e., SEN-C2-fCFC11_2050 and SEN-C2-fCFC11_2020 minus REF-C2, respectively) of the reactive chlorine mixing ratios with time is shown for the lower stratosphere (LS, near $50 \mathrm{hPa}$ ) and the upper stratosphere (US, near $2 \mathrm{hPa}$ ). Because all model simulations are operated in a "free-runningmode" (i.e., they do not have the same meteorology), the year-to-year difference (thin red and blue) curves as shown in Fig. 2 (and also in other figures shown afterwards) indicate the possible range of interannual fluctuation. Obvi- ously it takes about $10-15$ years (as expected) before the $\mathrm{ClO}_{x}$ values of the REF-C2 and SEN-C2-fCFC11_2050 simulations clearly diverge from each other. At the end of the SEN-C2-fCFC11_2050 simulation (i.e., in 2050), the resulting absolute (mean) difference in EMAC amounts to an approximate $6 \times 10^{-12} \mathrm{~mol} \mathrm{~mol}^{-1}$ increase in the LS and about a $50 \times 10^{-12} \mathrm{~mol} \mathrm{~mol}^{-1}$ increase in the US compared with the REF-C2 simulation. The vertical profile (structure) of the changes of the chlorine mixing ratios qualitatively resembles the reference $\mathrm{ClO}_{x}$ profile in EMAC (i.e., changes are biggest where the $\mathrm{ClO}_{x}$ mixing ratios are biggest), which displays a distinct maximum at about $2-3 \mathrm{hPa}$ (not shown). It turns out that the amount of chemically active chlorine species $\left(\mathrm{ClO}_{x}\right)$ in the SEN-C2-fCFC11_2050 simulation is about $17 \%$ larger on average than in the REF-C2 simulation in the US (above $30 \mathrm{~km}$ ) in the 2040s (i.e., the time period from 2041 to 2050); in the LS (below $30 \mathrm{~km}$ ) the respective amount of $\mathrm{ClO}_{x}$ is enhanced by about $30 \%$. As can be expected, the respective $\mathrm{ClO}_{x}$ differences between the SENC2-fCFC11_2020 and the REF-C2 simulations in the 2040s are clearly smaller, i.e., about $2 \times 10^{-12} \mathrm{~mol} \mathrm{~mol}^{-1}$ in the LS (about $14 \%$ ) and about $25 \times 10^{-12} \mathrm{~mol} \mathrm{~mol}^{-1}$ in the US (about $9 \%$ ).

\subsection{Total and partial ozone columns}

The impact of the enhanced atmospheric $\mathrm{ClO}_{x}$ content due to the constant CFC-11 surface mixing ratio after 2002 on total column ozone (TCO) is shown in Fig. 3. It illustrates the differences in the mean annual cycle for the last decade depending on the geographical latitude between the REF-C 2 and the SEN-C2-fCFC11_2050 simulations. The largest changes in the TCO values are found in both polar regions: in particular in the Northern Hemisphere during winter (December, January, and February) and in the Southern Hemisphere in late winter (August) to early spring (September and October). In the SEN-C2-fCFC11_2050 simulation, the TCO values are clearly reduced by up to about 30 Dobson units (DU) (in the order of $15 \%$ in the Southern Hemisphere) in comparison with the REF-C2 simulation. During other times of the year and in other latitudinal regions the identified TCO changes are much smaller: they are mostly below $\pm 5 \mathrm{DU}$.

A closer look at the near-global mean $\left(60^{\circ} \mathrm{S}-60^{\circ} \mathrm{N}\right)$ temporal behavior of the TCO (Fig. 4) indicates increasing ozone values in both simulations (Fig. 4a, for both simulations the solar cycle was removed, see figure caption). The results of the SEN-C2-fCFC11_2050 simulation show slightly smaller TCO values compared with REF-C2 and a slightly flatter slope of the linear trend line (this regression accounts for possible autocorrelation at lag 1 , see, e.g., the method described in Tiao et al., 1990). The linear regression based on the results of the REF-C2 simulation (here the black line presented in Fig. 4a) indicates an increase of 1.7 DU per decade for the TCO (annual near-global mean), whereas the linear regression based on the results of the SEN-C2-fCFC11_2050 

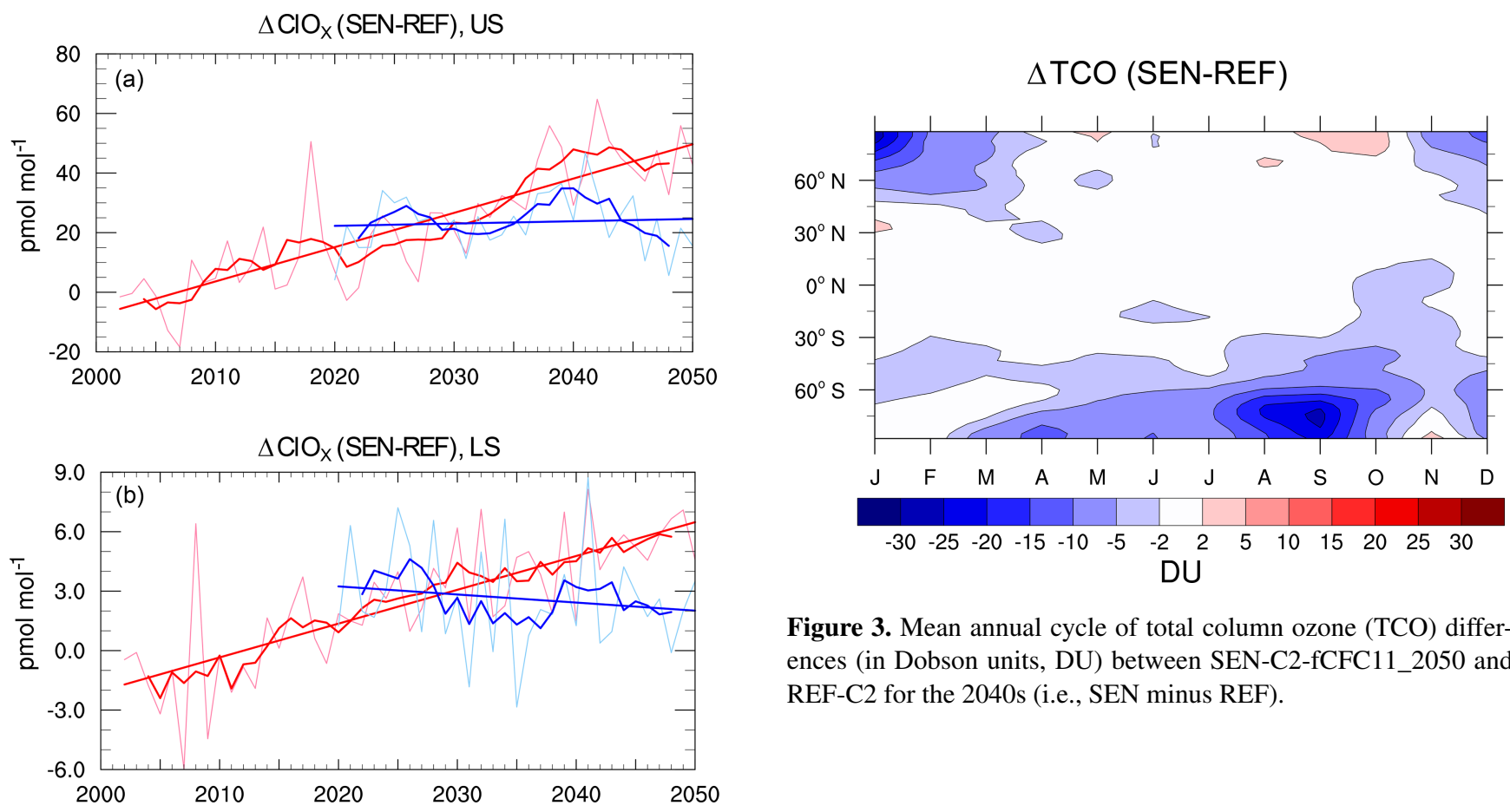

Figure 3. Mean annual cycle of total column ozone (TCO) differences (in Dobson units, DU) between SEN-C2-fCFC11_2050 and REF-C2 for the 2040s (i.e., SEN minus REF).

Figure 2. Temporal evolution of the annual global mean $\mathrm{ClO}_{x}$ mixing ratio differences (in $\mathrm{mol} \mathrm{mol}^{-1}$ ) at around $2 \mathrm{hPa}$ (US, a) and $50 \mathrm{hPa}$ (LS, b) between the SEN-C2-fCFC11_2050 and REF-C2 simulations (in red) and between the SEN-C2-fCFC11_2020 and REF-C2 simulations (in blue). The 11-year solar cycle (smoothed with a 1-2-1 filter) has been removed from both time series. The thicker curves in red and blue show the 5-year running means. The red and blue lines show the linear regression estimate of the unsmoothed time series.

(red line in Fig. 4a) shows a reduced increase of $1.3 \mathrm{DU}$ per decade. This finding is supported by the TCO difference (Fig. 4b), which indicates a small reduction in the TCO (in SEN-C2-fCFC11_2050) of up to about 2DU (in the order of less than $1 \%$ ) until 2050. The linear regression (again accounting for possible lag 1 autocorrelation) gives $-0.5 \mathrm{DU}$ per decade $( \pm 0.25 \mathrm{DU}$ per decade; given by two times the estimated standard error, which roughly corresponds to the $95 \%$ confidence interval and will be used throughout this paper as a measure of uncertainty). This effect can be rated as negligible in comparison with the expected annual fluctuations in this region. Therefore, in the following, we focus on the analyses of the polar regions, in particular on the Antarctic region in September. One reason for choosing the month September for further analyses of Antarctic ozone chemistry is that we found the most obvious ozone changes here. Another reason is that this month is less noisy than October (Solomon et al., 2016).

In the Southern Hemisphere polar region $\left(70-90^{\circ} \mathrm{S}\right)$ obvious ozone changes can be identified in September (Fig. 5). The mean differences of the TCO between the 2000s and the end of the simulation amount to about $20 \mathrm{DU}$, indicat-
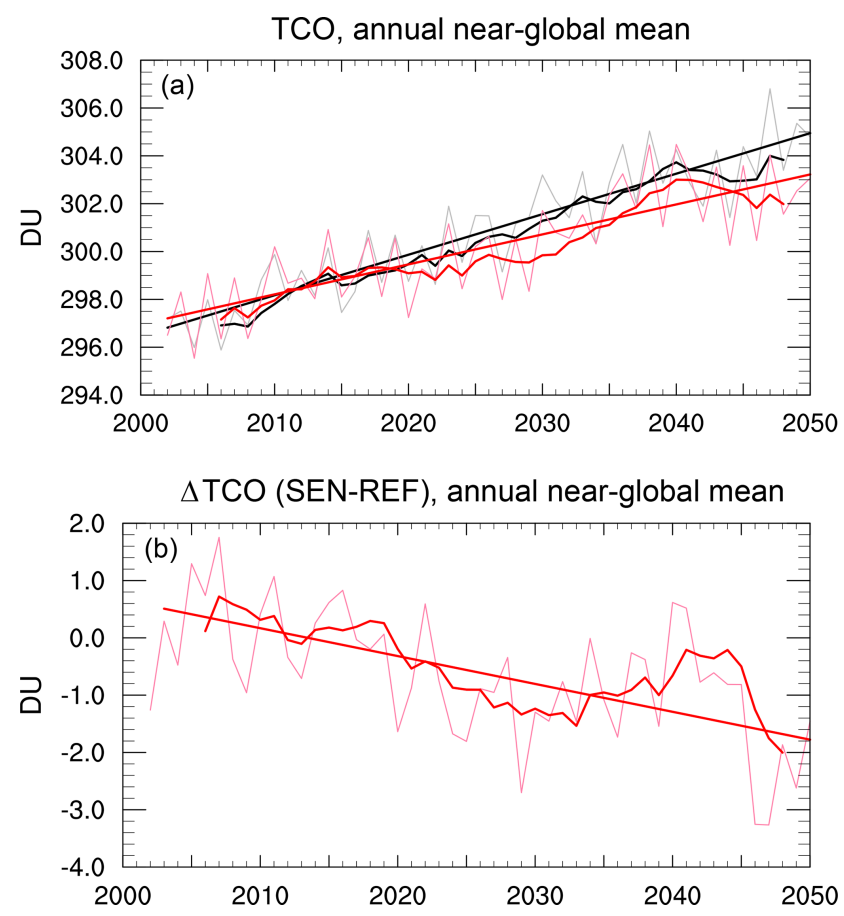

Figure 4. (a) Temporal evolution of total column ozone (TCO; in DU) for the annual near-global mean $\left(60^{\circ} \mathrm{S}-60^{\circ} \mathrm{N}\right)$ in REF-C2 (black curves) and SEN-C2-fCFC11_2050 (red curves). (b) TCO differences (in DU) between SEN-C2-fCFC11_2050 and REF-C2 (i.e., SEN minus REF). For the absolute TCO time series (a) the 11year solar cycle (smoothed with a 1-2-1 filter) has been removed. Thicker curves show the 5-year running means, respectively. The corresponding lines $(\mathbf{a}, \mathbf{b})$ show the respective linear regression estimates based on the unsmoothed data. 


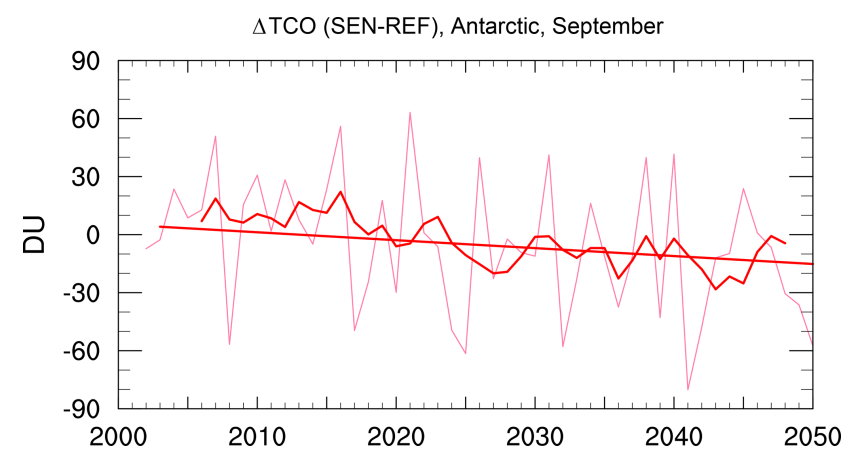

Figure 5. Temporal evolution of TCO differences (in DU) between SEN-C2-fCFC11_2050 and REF-C2 (i.e., SEN minus REF) for the Antarctic region $\left(70-90^{\circ} \mathrm{S}\right)$ in September. The thicker curve shows the 5-year running mean. The corresponding line shows the trend estimate between the unsmoothed time series using a multiple linear regression - including differences of temperature anomalies as the dependent variable - which accounts for possible autocorrelation with lag 1 (see text for details).

ing that the mean September ozone values in the SEN-C2fCFC11_2050 simulation are about $10 \%$ lower than in the REF-C2 simulation. The trend estimate gives $-4.1 \mathrm{DU}$ per decade $( \pm 1.7 \mathrm{DU}$ per decade). This trend estimate and the uncertainties were obtained by multiple linear regression, which accounts for possible lag 1 autocorrelation and uses the difference of the temperature anomalies (at $100 \mathrm{hPa}$ over $70-90^{\circ} \mathrm{S}$ ) from the REF-C2 and SEN-C2-fCFC11_2050 simulations as a second independent variable in addition to the linear trend. It is found that much of the interannual variability can be explained by including the difference of the polar temperature anomalies at $100 \mathrm{hPa}$ in the regression model. This agrees with Langematz et al. (2016), who used temperature anomalies to regress polar TCO. The temporal evolution of TCO differences and the size of the ozone disturbance found in the Northern Hemisphere polar region in January have the same order of magnitude (not shown), but the signal is more noisy because of the stronger dynamic variability.

Next, we look into stratospheric partial columns of ozone (PCO) in more detail with respect to the upper stratosphere (US, above about $30 \mathrm{~km}$, i.e., the $10 \mathrm{hPa}$ pressure level) and the lower stratosphere (LS, between 100 and $10 \mathrm{hPa}$ ) for the Antarctic region in September. Figure 6 shows the PCO differences for the US (panel a) and the LS (panel b) between the SEN-C2-fCFC11_2050 and the REF-C2 simulations. Both show the expected negative trend, indicating lower values at the end of the SEN-C2-fCFC11_2050 simulation in the late 2040s. Again the trends are obtained by the same regression model as for the TCO (see the previous paragraph), but for the US the temperatures at $10 \mathrm{hPa}$ were used. The mean PCO changes for the US of about $2 \mathrm{DU}$ are much smaller than those calculated for the LS (about $20 \mathrm{DU})$. The temporal evolution of the PCO differences in the LS show similar results as those found for the TCO dif-
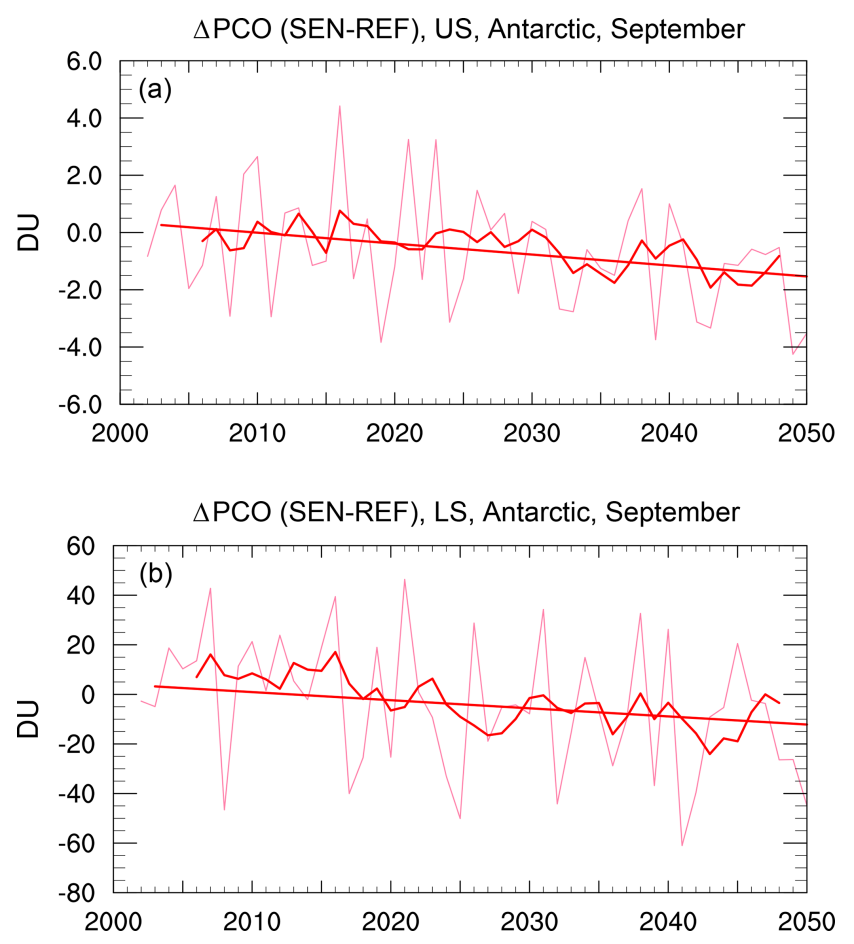

Figure 6. Temporal evolution of partial column ozone (PCO) differences (in DU) between SEN-C2-fCFC11_2050 and REF-C2 (i.e., SEN minus REF) for the Antarctic region (70-90 $\mathrm{S}$ ) in September. Panel (a) shows PCO values for the US (above $30 \mathrm{~km}$ ); panel (b) shows PCO values for the LS (below $30 \mathrm{~km}$ ). Red thicker curves show the respective 5-year running means. The corresponding lines show the trend estimates for the unsmoothed time series using a multiple linear regression - including differences of temperature anomalies as the dependent variable - which accounts for possible autocorrelation with lag 1 (see text for details).

ferences (Fig. 5): in the SEN-C2-fCFC11_2050 simulation the TCO is reduced by about $20 \mathrm{DU}$ until the year 2050 . The strongest signature of ozone change found in the polar LS points to the importance of heterogeneous chemical processes. Viewing the vertical profile of the differences of net ozone production rates of $\mathrm{ClO}_{x}$ between the REF-C 2 and the SEN-C2-fCFC11_2050 simulations in the 2040s clearly indicates an absolute minimum (i.e., less net ozone production in SEN-C2-fCFC11_2050) at around $50 \mathrm{hPa}$ and another relative minimum at about $1.5 \mathrm{hPa}$ in September (Fig. 8b; see explanation in Sect. 3.3). Moreover, looking at the PCO changes in middle- and lower-latitude regions $\left(60^{\circ} \mathrm{S}-60^{\circ} \mathrm{N}\right.$, not shown), the partial column differences clearly indicate that the small ozone differences detected in the TCO (Fig. 4b) are affected by ozone reductions of similar magnitudes in the US and the LS, displaying only small contributions to the TCO.

In Fig. 7, we compare the calculated differences between the SEN-C2-fCFC11_2050 and REF-C2 simulations as presented in Figs. 4-6 with the corresponding results derived 
from SEN-C2-fCFC11_2020 and REF-C2. In Fig. 7a-d, it is obvious that an immediate re-implementation of the Montreal Protocol eventually leads back to the direction of the expected ozone conditions around the end of the 2040s, as they are calculated in our REF-C2 simulation. In the REF-C2 simulation the model-diagnosed CFC-11 emissions are nearly zero after about 2030, whereas in the SEN-C2-fCFC11_2020 simulations they steadily decrease from higher values in 2020 down to zero around the year 2050. This is caused by the prescribed CFC-11 surface mixing ratio as indicated in Fig. 1.

\subsection{Stratospheric ozone budget}

In the following, a detailed analysis of individual ozone production and loss processes is carried out. This ozone budget analysis is used to investigate the role of separate chemical cycles and reactions, which are responsible for ozone production and loss in the stratosphere. For this analysis the MESSy tool "strato3bud" (cf. Meul et al., 2014, based on Jöckel et al., 2006) is employed. The respective reactions responsible for stratospheric ozone production (attributed to photolysis $\mathrm{h} v, \mathrm{HO}_{2}$, and $\mathrm{CH}_{3} \mathrm{O}_{2}$ ) and loss (attributed to $\mathrm{O}_{x}, \mathrm{NO}_{x}, \mathrm{HO}_{x}, \mathrm{ClO}_{x}$, and $\mathrm{BrO}_{x}$ ) are described by Meul et al. (2014, see their Table 2). In Fig. 8, the results of this budget analysis are shown as changes of the ozone production rate between the SEN-C2-fCFC11_2050 and the REF$\mathrm{C} 2$ simulations $\left(\Delta P_{\mathrm{SEN}-\mathrm{REF}}^{\mathrm{prc}}\right)$ with respect to the total production rate in the REF-C2 simulation. The explicit formula for calculating the changes of the ozone production rate at a certain level is given as

$$
\Delta P_{\mathrm{SEN}-\mathrm{REF}}^{\mathrm{prc}}(\mathrm{lev})=\frac{\sum_{\text {lat } \in R} P_{\mathrm{SEN}}^{\mathrm{prc}}(\text { lat, lev })-\sum_{\text {lat } \in R} P_{\mathrm{REF}}^{\mathrm{prc}}(\text { lat }, \text { lev })}{\sum_{\text {levlat } \in R} \sum_{\mathrm{REF}}(\text { lat }, \text { lev })} .
$$

Here, $P$ denotes the temporal mean and zonally summed ozone production rate (molecules $\mathrm{s}^{-1}$ ). The subscript denotes the respective simulations, and the "prc" superscript denotes which process $\left(\mathrm{h} v, \mathrm{HO}_{2}, \mathrm{CH}_{3} \mathrm{O}_{2}, \mathrm{O}_{x}, \mathrm{NO}_{x}, \mathrm{HO}_{x}\right.$, $\mathrm{ClO}_{x}$, and $\mathrm{BrO}_{x}$ ) is analyzed. Loss cycles are regarded as negative production rates. Further, the superscript "tot" denotes the sum of all positive production rates (namely of $\mathrm{h} v, \mathrm{HO}_{2}$, and $\mathrm{CH}_{3} \mathrm{O}_{2}$ ) and the summation goes over all latitudes, which lie in the respective latitudinal band $\mathrm{R}$. Here we show profiles of $\Delta P_{\mathrm{SEN}-\mathrm{REF}}$ for the annual global mean and the Southern Hemisphere polar region $\left(70-90^{\circ} \mathrm{S}\right)$ during September 2041-2050. In the Antarctic spring season, (Fig. 8b) it is obvious that the enhanced content of reactive chlorine in the SEN-C2-fCFC11_2050 simulation is responsible for the intensified ozone loss in the LS (around $50 \mathrm{hPa}$ ) and the US (around $1.5 \mathrm{hPa}$ ). In the LS, ozone loss through reactive bromine compounds $\left(\mathrm{BrO}_{x}=\mathrm{Br}+\mathrm{BrO}+\mathrm{HOBr}+\right.$ $\mathrm{BrCl}+2 \mathrm{Br}_{2}$ ) is also enhanced, which is probably related to the enhanced chlorine loading as a result of ozone loss due to the reaction of $\mathrm{BrO}$ with $\mathrm{ClO}$ (see Table 2 in Meul et al., 2014, which specifies the reactions that are considered in our analysis of ozone production and loss cycles). Conversely, as a consequence of more available chlorine, other loss cycles or production processes show a tendency to compensate for the enhanced ozone destruction by chlorine. For instance, the catalytic $\mathrm{NO}_{x}$ cycle shows some balancing in the altitude region between about $19 \mathrm{~km}(50 \mathrm{hPa})$ and the stratopause (about $0.7 \mathrm{hPa}$ ). This means that the ozone depletion by $\mathrm{NO}_{x}$ is clearly reduced (i.e., a relative ozone production) in the SEN-C2-fCFC11_2050 compared with the REF-C2 simulation above about $40 \mathrm{hPa}$ (see the red line in Fig. 8, which indicates the change of the net ozone production rate) in the 2040s. It is, however, not straightforward to further disentangle the underlying processes of the most relevant chemical cycles, as the underlying kinetic system is highly nonlinear. The system in the SEN-C2-fCFC11_2050 simulation is heading towards a different chemical equilibrium, due to the distribution of educts and the temperature change. The results with respect to the global annual means of ozone production and loss in the 2040s shown in Fig. 8a indicate that below about $50 \mathrm{hPa}$ no obvious changes are detected. Above $20 \mathrm{~km}$ the ozone loss is strongly affected by reactive chlorine, and, again, some compensation effects due to other competing ozone loss cycles are clearly identified in the US. The positive values with respect to the photolysis rates indicate a slight downward shift of the ozone layer (ozone maximum) to lower altitudes. This is probably due to enhanced ozone loss via chlorine at higher altitudes, which allows more UV radiation to reach lower altitudes, where this additional radiation then causes higher photolysis rates. Overall, the red line in the Fig. 8a indicates that the change in the net ozone production rate is nearly zero at all altitudes due to these compensating effects.

The analogous ozone budget analysis is carried out for changes in the ozone production rate between the SEN-C2fCFC11_2020 and the REF-C2 simulations. As expected, the vertical dependence of the ozone production rates in the 2040s looks similar to those in the analysis of the SENC2-fCFC11_2050 simulation (not shown), namely (1) the global annual means of the ozone production and loss below about $20 \mathrm{~km}(50 \mathrm{hPa})$ do not indicate obvious changes. Higher up ozone loss is strongly affected by reactive chlorine, and, again, some compensation effects in the US due to other competing ozone loss cycles are clearly identified; however, all ozone production rate changes are about half as strong as those found between the SEN-C2-fCFC11_2050 and REF-C2 simulations (see Fig. 8a). (2) In the Antarctic region during September in the 2040s the intensified ozone loss in the $\mathrm{LS}$ (around $50 \mathrm{hPa}$ ) via the $\mathrm{ClO}_{x}$ and $\mathrm{BrO}_{x}$ cycles are again obvious, but the ozone destruction rates are only one-third of the magnitude of that found between the SENC2-fCFC11_2050 and REF-C2 simulations (see Fig. 8b).

Finally, to check the possible impact of temperature changes due to enhanced CFC-11 concentrations on ozone 

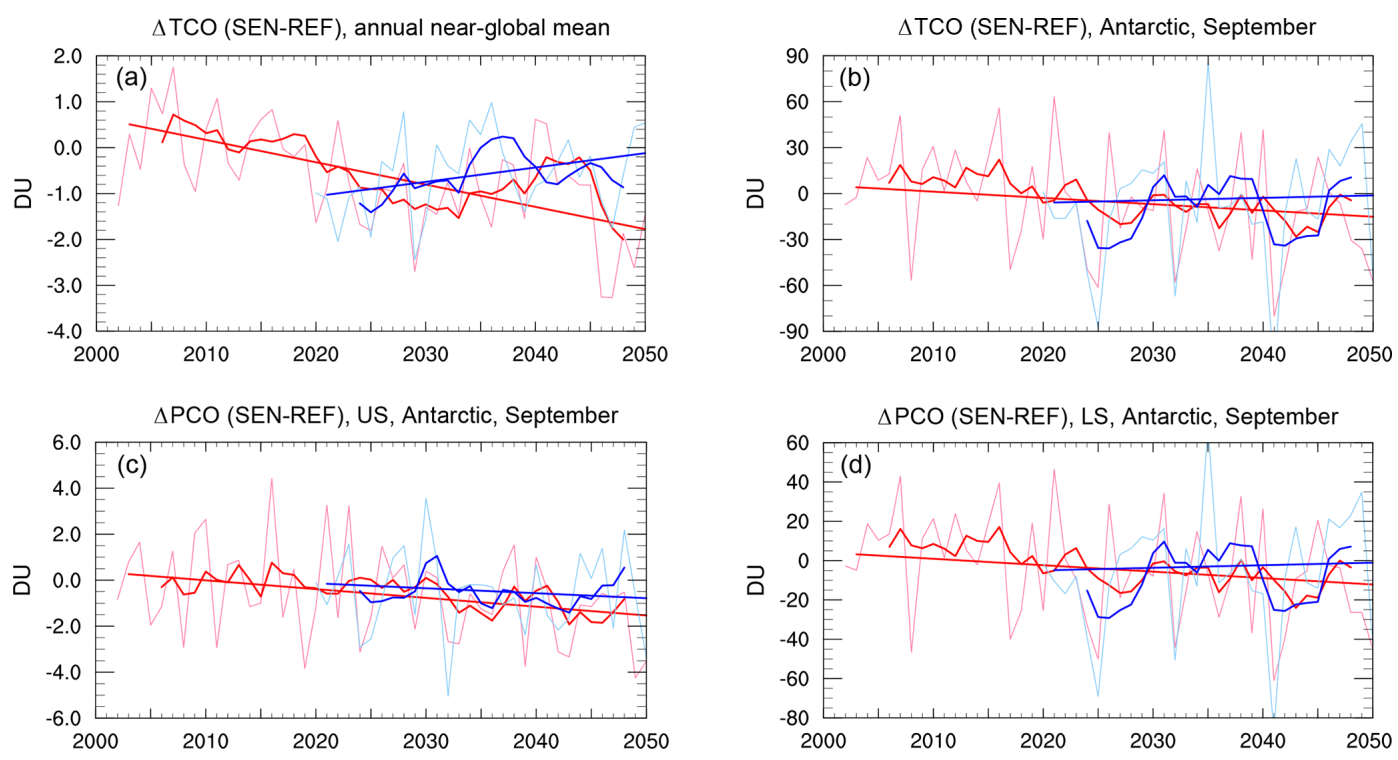

Figure 7. Different temporal evolution of column ozone differences (in DU) between the individual sensitivity simulations and the reference simulation (in DU): SEN-C2-fCFC11_2050 minus REF-C2 values are indicated in red, and SEN-C2-fCFC11_2020 minus REF-C2 values are shown in blue. (a) TCO for the annual near-global mean $\left(60^{\circ} \mathrm{S}-60^{\circ} \mathrm{N}\right)$; (b) TCO for the Antarctic $\left(70-90^{\circ} \mathrm{S}\right)$ in September; (c) PCO for the Antarctic $\left(70-90^{\circ} \mathrm{S}\right)$ in the US in September; (d) PCO for the Antarctic (70-90 S) in the LS in September. The red and blue lines show the trend estimates for the unsmoothed time series using a multiple linear regression - including differences in temperature anomalies as the dependent variable - which accounts for possible autocorrelation with lag 1 (see text for details).

chemistry, we analyze the overall temperature trends in the US (near $1 \mathrm{hPa}$ ) and LS (near $50 \mathrm{hPa}$ ) as well as the differences between REF-C2 and SEN-C2-fCFC11_2050. The global annual mean long-term temperature behavior in the REF-C2 simulation indicates a cooling of about $1 \mathrm{~K}$ in the LS and of about $3 \mathrm{~K}$ in the US from the early 2000s until to the year 2050. The temperature difference between REF-C2 and SEN-C2-fCFC11_2050 amounts to an additional cooling of about $0.3 \mathrm{~K}$ in the US in the SEN-C2-fCFC11_2050 simulation, whereas no obvious change in the long-term behavior can be identified in the LS (not shown). It is difficult to separate the individual contributions of the additional cooling in a coupled CCM simulation, i.e., radiative cooling due to enhanced CFC-11 concentrations and due to less ozone in the stratosphere caused by the enhanced chlorine loading without additional diagnostics. We assume that both processes will contribute to the calculated additional cooling in the SEN-C2-fCFC11_2050 simulation.

Taking a closer look at the Southern Hemisphere polar region in spring, the REF-C2 simulation indicates a clear cooling trend of about $4 \mathrm{~K}$ in the US (near $1 \mathrm{hPa}$ ) until 2050, whereas no obvious trend can be identified in the LS (not shown). With respect to the temperature differences of SENC2-fCFC11_2050 and REF-C2, the US does not show a clear change, whereas in the LS the SEN-C2-fCFC11 simulation suggests some additional cooling from the early 2000 s until 2050 by about $2 \mathrm{~K}$. However, this difference is superposed by large interannual fluctuations.
With this in mind, we can try to evaluate the calculated ozone differences in the sensitivity simulations in comparison to REF-C2. With respect to the global mean in the US, on the one hand, enhanced chlorine mixing ratios lead to enhanced ozone depletion via the catalytic ozone destruction cycle; on the other hand, the extra cooling is known to create a reduction of the ozone depletion rates by gas-phase chemistry (e.g., Haigh and Pyle, 1982). It was found that the net effect here is slightly negative, i.e., there are indications that ozone differences between REF-C2 and the sensitivity simulations in the US are dominated by the enhanced chlorine content. With respect to the global mean in the LS, where no clear cooling is simulated, the smaller ozone values are mainly caused by the enhanced chlorine content.

Looking closer at the south polar region in spring, it is obvious that the enhanced chlorine content is again mostly responsible for the slightly reduced PCO in the SEN-C2fCFC11_2050 simulation in the US (Fig. 6a). In the LS, where heterogeneous chemical processes are the most important drivers of ozone changes, the enhanced chlorine mixing ratios intensify the ozone destruction. This leads to significantly reduced PCO over the time (Fig. 6b), which eventually leads to the indicated (slight) extra cooling of the polar lower stratosphere in spring. However, a first analysis of polar stratospheric cloud (PSC) statistics for the REF-C2 and SEN-C2-fCFC11_2050 simulations did not display a considerable trend in the PSC surface area (not shown). Therefore, we cannot identify any hint of enhanced chlorine activation. 


\section{Ozone production rate}
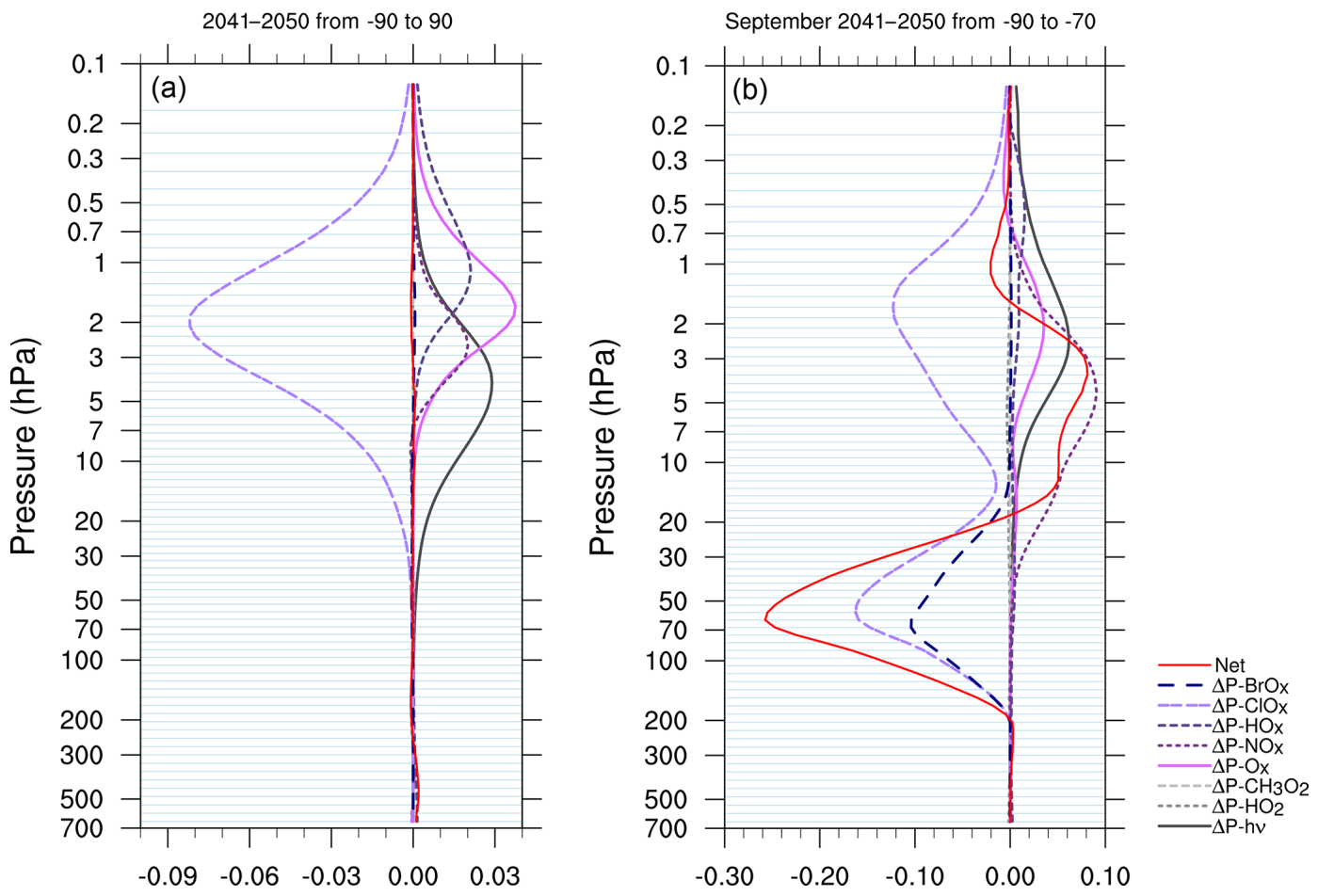

Figure 8. The relative change in ozone production rates (in \%), which are normalized to the total column production (through photolysis $\mathrm{h} v, \mathrm{HO}_{2}$, and $\mathrm{CH}_{3} \mathrm{O}_{2}$ ) in the REF-C2 simulation. For the individual ozone production and loss processes, mean differences are shown that have been derived from the REF-C2 and SEN-C2-fCFC11_2050 (i.e., SEN minus REF) simulations for the 2040s (from 2041 to 2050). The change in the net ozone production rate, which refers to the sum of all changes, is indicated by the red line. Panel (a) shows the mean annual global mean profiles, and panel (b) shows the values for the south polar region $\left(70-90^{\circ} \mathrm{S}\right)$ in September. Negative values indicate an intensified ozone loss or a decreased ozone production in the SEN-C2-fCFC11_2050 simulation, whereas higher values indicate more ozone production or less loss via a specific process. Thin horizontal lines indicate the nearest pressure levels to the model grid boxes.

\section{Discussions and conclusion}

After the detection of an unexpected and persistent increase in global emissions of CFC-11 (Montzka et al., 2018; see also update in Harris et al., 2019), it is still unclear (i) how much these additional emissions have already affected stratospheric ozone, (ii) how the CFC-11 emissions could further develop in the coming years, and (iii) how large the potential for a disturbance of the temporal evolution of the ozone layer is. The discussions during the international CFC-11 Symposium in Vienna (March 2019) on the unexpected increase of CFC-11 emissions came to the conclusion that a major problem is the creation of a realistic assessment of future CFC-11 levels (Harris et al., 2019). There are many factors that have significant uncertainties, such as the role of bank emissions or a possible co-production of CFC-12 $\left(\mathrm{CF}_{2} \mathrm{Cl}_{2}\right)$ with $\mathrm{CFC}-11$. There was a general acceptance that higher CFC-11 emissions are creating enhanced ozone depletion, but so far the corresponding magnitudes of ozone disturbances are uncertain. This study aims to estimate possible ozone changes due to enhanced CFC-11 values in recent and coming years, while the amount of other ODS are declining as expected. For that reason, a simplified study based on CCM simulations is conducted to (1) roughly estimate the implications of a constant mean CFC-11 surface mixing ratio for ozone depletion instead of reducing CFC-11 on longer timescales, and (2) to establish approximately how strong the maximum ozone effect is due to the additional CFC-11 emissions in recent years. To keep things as simple as possible we do not consider regional differences with respect to CFC-11 emissions in our sensitivity simulations. From our point of view, considering regional differences would not have relevant effects on the results presented due to the long lifetime of CFC-11 (e.g., Rigby et al., 2013; Engel et al., 2018), which leads to global mixing (Hoffmann et al., 2014). Our simplified approach assumes an extreme boundary condition (i.e., constant $\mathrm{CFC}-11$ surface mixing ratios until the year 2050 in SEN-C2-fCFC11_2050 and until the year 2019 in SEN-C2-fCFC11_2020), which is justified as a more realistic approach with respect to future CFC-11 levels is currently not available (Harris et al., 2019). Therefore, the results pre- 
sented should not at all be taken as a robust prediction of future conditions.

The results presented generally indicate that in particular the ozone layer over the Arctic and Antarctic in late winter and spring is affected by the prescribed CFC-11 surface mixing ratio change. In our case, at the end of the SEN-C2fCFC11_2050 simulation, the impact on the TCO culminates in a maximum ozone decrease of up to $30 \mathrm{DU}$ in both polar regions (Fig. 3). The calculated ozone changes in midlatitude and tropical regions are surprisingly small (less than $\pm 5 \mathrm{DU}$ ) and are therefore generally not significant in the sense that the range of variability is in the same order of magnitude. An estimate of possible ozone changes in the late 2040s based on the perturbation of "equivalent effective stratospheric chlorine" (EESC) may lead to similar results, but appropriate explanations are lacking. Therefore, we perform a detailed ozone budget analysis of such sensitivity simulations for the first time, showing interesting results with regard to compensation and buffering effects associated with different production and loss cycles. It can be seen from our results that the strengthened ozone depletion by enhanced chlorine is partly compensated for by other ozone-depleting catalytic cycles (e.g., $\mathrm{NO}_{x}$ ) and other molecules (e.g., $\mathrm{HO}_{2}$ ). With respect to the global mean picture, there is no large TCO difference visible, as the effects of ozone production and loss processes are nearly canceling. However, in the polar regions, although there are also compensating effects, the signal is noteworthy in spring (e.g., about $20 \mathrm{DU}$ for the Antarctic region). We identify where (altitude) and when the ozone amount is decreased in the SEN-C2-fCFC11_2050 simulation compared with REF-C2. The ozone response to CFC-11 changes looks quasi-linear, but the processes in the background are obviously nonlinear.

Finally, based on the results of our SEN-C2-fCFC11_2050 simulation, we try to approximately estimate the possible shift of the closure date of the ozone hole over Antarctica under the implied conditions of this sensitivity. To do so, we look at the temporal evolution of the total stratospheric $\mathrm{ClO}_{x}$ loading in the REF-C2 (started in the middle of the 20th century) and the SEN-C2-fCFC11_2050 simulations. In the REF-C2 simulation $\mathrm{ClO}_{x}$ values are strongly increasing from 1960 onwards and are highest at the end of the 1990s. Starting in the 2000s the $\mathrm{ClO}_{x}$ concentration is decreasing. The 1980 value of the REF-C2 simulation can be regarded as a reference for chlorine conditions before the ozone hole appeared. This "pre-ozone-hole" chlorine content is reached again around the year 2050 in our REF-C2 simulation, which is some years earlier than the multi-model mean based on all REF-C2 simulations as calculated by Dhomse et al. (2018). By extrapolating the linear regression line of the $\mathrm{ClO}_{x}$ content (for 2002-2050) of the SEN-C2-fCFC11_2050 simulation (not shown) into the future, we estimate that a pre-ozonehole, i.e., " 1980 ", $\mathrm{ClO}_{x}$ loading is likely to be reached before 2070. Therefore, we can roughly estimate a maximum delay of the closure of the ozone hole of less than about 20 years when keeping the CFC-11 surface mixing ratio at a 2002 level versus a decline in the CFC-11 surface mixing ratio which would occur due to adherence to the Montreal Protocol. Considering that Dhomse et al. (2018) determined that the closure of the ozone hole would occur by the year 2060 and that the $1 \sigma$ standard deviation was in the range of about \pm 5 years (see also Fig. 4.22 by Langematz et al., 2018), this indicates that the calculated effects of a constant CFC-11 surface mixing ratio could have a non-negligible effect on the closure date of the ozone hole. This finding is in line with other model results mentioned by Harris et al. (2019), who stated that the closure of the ozone hole and ozone recovery as a whole will be delayed depending on the CFC-11 emission levels. A first estimate presented in WMO (2018) showed that if total CFC-11 emissions were to continue at the levels experienced from 2002 to $2016\left(67 \mathrm{Gg} \mathrm{yr}^{-1}\right)$, the return of midlatitude and polar EESC to the 1980 value would be delayed by about 7 years and 20 years, respectively. For the Arctic region, enhanced stratospheric chlorine content means that there is the possibility of stronger ozone depletion under specific dynamic conditions (i.e., a stable and cold polar vortex until March) for a slightly longer time period (e.g., Dameris et al., 2014).

The results presented do not show dramatic consequences for the global mean ozone layer due to an enhanced CFC-11 surface mixing ratio for the coming years, but indicate relevant changes in the polar regions in winter and spring. In light of our results regarding chemical feedback processes, which dilute the effects due to enhanced CFC-11 levels in parts, compliance with the guidelines of the Montreal Protocol is absolutely necessary. Without a continued strong regulation of CFC-11 and other ODS emissions (e.g., Laube et al., 2014; Hossani et al., 2017), the recovery of the ozone layer could be significantly affected - including the timescale of ozone hole closure - and this should be avoided!

Code and data availability. The Modular Earth Submodel System (MESSy) is continuously developed and applied by a consortium of institutions. Use of MESSy and access to the source code is licensed to all affiliates of institutions that are members of the MESSy Consortium. Institutions can become a member of the MESSy Consortium by signing the MESSy Memorandum of Understanding. More information can be found on the MESSy Consortium website (http://www.messy-interface.org, last access: 12 November 2019).

Author contributions. Both sensitivity simulations were set up and carried out by PJ with support from MD. MD structured and composed the paper. All authors analyzed the model data and compiled the results, and all three authors contributed to the paper.

Competing interests. The authors declare that they have no conflict of interest. 
Acknowledgements. The authors would like to thank Heidi Huntrieser for her internal review and her useful suggestions that improved the paper. The authors are also grateful to the two anonymous referees for their helpful comments on the paper. The work described in this paper has received funding from the Initiative and Networking Fund of the Helmholtz Association through the "Advanced Earth System Modelling Capacity (ESM)" project. The authors also acknowledge financial support from the DLR internal project KliSAW (Klimarelevanz von atmosphärischen Spurengasen, Aerosolen und Wolken) and the Research Unit SHARP of the Deutsche Forschungsgemeinschaft (DFG). The model simulations were performed at the German Climate Computing Center (DKRZ) supported by the Bundesministerium für Bildung und Forschung (BMBF). The NCAR Command Language (NCL, 2018) was used for data analysis and to create some of the figures in this study. NCL is developed by UCAR/NCAR/CISL/TDD and is available online at https://doi.org/10.5065/D6WD3XH5. CDO (climate data operators; Schulzweida, 2019) was employed for processing the data. The authors wish to thank all contributors to the ESCiMo (Earth System Chemistry integrated Modelling) project, which provided the model configuration and initial conditions for this study. The World Climate Research Programme's Working Group on Coupled Modelling, which is responsible for CMIP, is also acknowledged, and the authors are thankful to the HadGEM climate modeling group for producing their model output and making it available for use. With respect to CMIP, the United States Department of Energy's Program for Climate Model Diagnosis and Intercomparison provides coordinating support and led development of the software infrastructure in partnership with the Global Organization for Earth System Science Portals.

Financial support. This research has been supported by the Deutsche Forschungsgemeinschaft (DFG; Forschergruppe SHARP), the Helmholtz-Gemeinschaft (Advanced Earth System Modelling Capacity, ESM), and the Deutsches Zentrum für Luftund Raumfahrt e.V. (DLR; KliSAW project).

The article processing charges for this open-access

publication were covered by a Research

Centre of the Helmholtz Association.

Review statement. This paper was edited by Jens-Uwe Grooß and reviewed by two anonymous referees.

\section{References}

Carpenter, L. J., Reimann, S., Burkholder, J. P., Clerbaux, C., Hall, B. D., Hossaini, R., Laube, J. C., and Yvon-Lewis, S. A.: Update on Ozone-Depleting Substances (ODSs) and other gases of interest to the Montreal Protocol, Chapter 1 in Scientific Assessment of Ozone Depletion: 2014, Global Ozone Research and Monitoring, Project-Report No. 55, World Meteorological Organization, Geneva, Switzerland, 2014.

Dameris, M., Godin-Beekmann, S., Alexander, S., Braesicke, P., Chipperfield, M., de Laat, A. T. J., Orsolini, Y., Rex, M., and Santee, M. L.: Update on Polar ozone: Past, present, and future,
Chapter 3 in Scientific Assessment of Ozone Depletion: 2014, Global Ozone Research and Monitoring Project - Report No. 55, World Meteorological Organization, Geneva, Switzerland, 2014. Daniel, J. S., Velders, G. J. M., Morgenstern, O., Toohey, D. W., Wallington, T. J., Wuebbles, D. J., Akiyoshi, H., Bais, A. F., Fleming, E. L., Jackman, C. H., Kuijpers, L. J. M., McFarland, M., Montzka, S. A., Ross, M. N., Tilmes, S., and Tully, M. B.: A Focus on Information and Options for Policymakers, Chapter 5 in Scientific Assessment of Ozone Depletion: 2010, Global Ozone Research and Monitoring, Project-Report No. 52, 516 pp., Geneva, Switzerland, 2011.

Dhomse, S. S., Kinnison, D., Chipperfield, M. P., Salawitch, R. J., Cionni, I., Hegglin, M. I., Abraham, N. L., Akiyoshi, H., Archibald, A. T., Bednarz, E. M., Bekki, S., Braesicke, P., Butchart, N., Dameris, M., Deushi, M., Frith, S., Hardiman, S. C., Hassler, B., Horowitz, L. W., Hu, R.-M., Jöckel, P., Josse, B., Kirner, O., Kremser, S., Langematz, U., Lewis, J., Marchand, M., Lin, M., Mancini, E., Marécal, V., Michou, M., Morgenstern, O., O’Connor, F. M., Oman, L., Pitari, G., Plummer, D. A., Pyle, J. A., Revell, L. E., Rozanov, E., Schofield, R., Stenke, A., Stone, K., Sudo, K., Tilmes, S., Visioni, D., Yamashita, Y., and Zeng, G.: Estimates of ozone return dates from ChemistryClimate Model Initiative simulations, Atmos. Chem. Phys., 18, 8409-8438, https://doi.org/10.5194/acp-18-8409-2018, 2018.

Engel, A., Strunk, M., Müller, M., Haase, H. P., Poss, C., Levin, I., and Schmidt, U.: Temporal development of total chlorine in the high-latitude stratosphere based on reference distributions of mean age derived from $\mathrm{CO}_{2}$ and $\mathrm{SF}_{6}$, J. Geophys. Res., 107, 4136, https://doi.org/10.1029/2001JD000584, 2002.

Engel, A., Rigby, M., Burkholder, J. B., Fernandez, R. P., Froidevaux, L., Hall, B. D., Hossaini, R., Saito, T., Vollmer, M. K., and Yao, B.: Update on Ozone-Depleting Substances (ODSs) and other gases of interest to the Montreal Protocol, Chapter 1 in Scientific Assessment of Ozone Depletion: 2018, Global Ozone Research and Monitoring, Project-Report No. 58, World Meteorological Organization, Geneva, Switzerland, 2018.

Eyring, V., Lamarque, J.-F., Hess, P., Arfeuille, F., Bowman, K., Chipperfield, M. P., Duncan, B., Fiore, A., Gettelman, A., Giorgetta, M. A., Granier, C., Hegglin, M., Kinnison, D., Kunze, M., Langematz, U., Luo, B., Martin, R., Matthes, K., Newman, P. A., Peter, T., Robock, A., Ryerson, T., Saiz-Lopez, A., Salawitch, R., Schultz, M., Shepherd, T. G., Shindell, D., Stähelin, J., Tegtmeier, S., Thomason, L., Tilmes, S., Vernier, J.-P., Waugh, D. W., and Young, P. J.: Overview of IGAC/SPARC Chemistry-Climate Model Initiative (CCMI) Community simulations in support of upcoming ozone and climate assessments, SPARC Newsletter, 40, 48-66, 2013.

Haigh, J. D. and Pyle, J. A.: Ozone perturbation experiments in a two-dimensional circulation model, Q. J. Roy. Meteorol. Soc., 108, 551-574, 1982.

Harris, N. R. P., Montzka, S. A., and Newman P. A.: Report on the international symposium of the unexpected increase in emissions of ozone-depleting CFC-11, SPARC Newsletter, 53, 9-18, 2019.

Hoffmann, L., Hoppe, C. M., Müller, R., Dutton, G. S., Gille, J. C., Griessbach, S., Jones, A., Meyer, C. I., Spang, R., Volk, C. M., and Walker, K. A.: Stratospheric lifetime ratio of CFC-11 and CFC-12 from satellite and model climatologies, Atmos. Chem. Phys., 14, 12479-12497, https://doi.org/10.5194/acp-14-124792014, 2014. 
Hossani, R., Chipperfield, M. P., Montzka, S. A., Leeson, A. A., Dhomse, S. S., and Pyle, J. A.: The increasing threat to stratospheric ozone from dichloromethane, Nat. Commun., 8, 15962, https://doi.org/10.1038/ncomms15962, 2017.

Jöckel, P., Tost, H., Pozzer, A., Brühl, C., Buchholz, J., Ganzeveld, L., Hoor, P., Kerkweg, A., Lawrence, M. G., Sander, R., Steil, B., Stiller, G., Tanarhte, M., Taraborrelli, D., van Aardenne, J., and Lelieveld, J.: The atmospheric chemistry general circulation model ECHAM5/MESSy1: consistent simulation of ozone from the surface to the mesosphere, Atmos. Chem. Phys., 6, 50675104, https://doi.org/10.5194/acp-6-5067-2006, 2006.

Jöckel, P., Tost, H., Pozzer, A., Kunze, M., Kirner, O., Brenninkmeijer, C. A. M., Brinkop, S., Cai, D. S., Dyroff, C., Eckstein, J., Frank, F., Garny, H., Gottschaldt, K.-D., Graf, P., Grewe, V., Kerkweg, A., Kern, B., Matthes, S., Mertens, M., Meul, S., Neumaier, M., Nützel, M., Oberländer-Hayn, S., Ruhnke, R., Runde, T., Sander, R., Scharffe, D., and Zahn, A.: Earth System Chemistry integrated Modelling (ESCiMo) with the Modular Earth Submodel System (MESSy) version 2.51, Geosci. Model Dev., 9, 1153-1200, https://doi.org/10.5194/gmd-9-1153-2016, 2016.

Jones, C. D., Hughes, J. K., Bellouin, N., Hardiman, S. C., Jones, G. S., Knight, J., Liddicoat, S., O’Connor, F. M., Andres, R. J., Bell, C., Boo, K.-O., Bozzo, A., Butchart, N., Cadule, P., Corbin, K. D., Doutriaux-Boucher, M., Friedlingstein, P., Gornall, J., Gray, L., Halloran, P. R., Hurtt, G., Ingram, W. J., Lamarque, J.-F., Law, R. M., Meinshausen, M., Osprey, S., Palin, E. J., Parsons Chini, L., Raddatz, T., Sanderson, M. G., Sellar, A. A., Schurer, A., Valdes, P., Wood, N., Woodward, S., Yoshioka, M., and Zerroukat, M.: The HadGEM2-ES implementation of CMIP5 centennial simulations, Geosci. Model Dev., 4, 543-570, https://doi.org/10.5194/gmd-4-543-2011, 2011.

Kerkweg, A., Sander, R., Tost, H., and Jöckel, P.: Technical note: Implementation of prescribed (OFFLEM), calculated (ONLEM), and pseudo-emissions (TNUDGE) of chemical species in the Modular Earth Submodel System (MESSy), Atmos. Chem. Phys., 6, 3603-3609, https://doi.org/10.5194/acp-6-3603-2006, 2006.

Langematz, U., Schmidt, F., Kunze, M., Bodeker, G. E., and Braesicke, P.: Antarctic ozone depletion between 1960 and 1980 in observations and chemistry-climate model simulations, Atmos. Chem. Phys., 16, 15619-15627, https://doi.org/10.5194/acp-16-15619-2016, 2016.

Langematz, U., Tully, M., Calvo, N., Dameris, M., de Laat, A. T. J., Klekociuk, A., Müller, R., and Young, P.: Polar stratospheric ozone: past, present, and future, Chapter 4 in Scientific Assessment of Ozone Depletion: 2018, Global Ozone Research and Monitoring Project-Report No. 58, World Meteorological Organization, Geneva, Switzerland, 2018.

Laube, J. C., Newland, M. J., Hogan, C., Brenninkmeijer, C. A. M., Fraser, P. J., Martinerie, P., Oram, D. E., Reeves, C. E., Röckmann, T., Schwander, J. Witrante., and Sturges, W. T.: Newly detected ozone-depleting substances in the atmosphere, Nat. Geosci., 7, 266-269, https://doi.org/10.1038/NGEO2109, 2014.

Meul, S., Langematz, U., Oberländer, S., Garny, H., and Jöckel, P.: Chemical contribution to future tropical ozone change in the lower stratosphere, Atmos. Chem. Phys., 14, 2959-2971, https://doi.org/10.5194/acp-14-2959-2014, 2014.

Montzka, S. A., Dutton, R., Yu, P., Ray, E., Portmann, R. W., Daniel, J. S., Kuijpers, L., Hall, B. D., Mondeel, D., Siso, C., Nance,
D. J., Rigby, M., Manning, A. J., Hu, L., Moore, F., Miller, B. R., and Elkins, J. W.: A persistent and unexpected increase in global emissions of ozone-depleting CFC-11, Nature, 557, 413417, https://doi.org/10.1038/s41586-018-0106-2, 2018.

NCL: The NCAR Command Language (Version 6.5.0) [Software], Boulder, Colorado, UCAR/NCAR/CISL/TDD, https://doi.org/10.5065/D6WD3XH5, 2018.

Newman, P. A., Oman, L. D., Douglass, A. R., Fleming, E. L., Frith, S. M., Hurwitz, M. M., Kawa, S. R., Jackman, C. H., Krotkov, N. A., Nash, E. R., Nielsen, J. E., Pawson, S., Stolarski, R. S., and Velders, G. J. M.: What would have happened to the ozone layer if chlorofluorocarbons (CFCs) had not been regulated?, Atmos. Chem. Phys., 9, 2113-2128, https://doi.org/10.5194/acp-9-21132009, 2009.

Rigby, M., Prinn, R. G., O’Doherty, S., Montzka, S. A., McCulloch, A., Harth, C. M., Mühle, J., Salameh, P. K., Weiss, R. F., Young, D., Simmonds, P. G., Hall, B. D., Dutton, G. S., Nance, D., Mondeel, D. J., Elkins, J. W., Krummel, P. B., Steele, L. P., and Fraser, P. J.: Re-evaluation of the lifetimes of the major CFCs and $\mathrm{CH}_{3} \mathrm{CCl}_{3}$ using atmospheric trends, Atmos. Chem. Phys., 13, 2691-2702, https://doi.org/10.5194/acp-13-2691-2013, 2013.

Rigby, M., Park, S., Saito, T., Western, L. M., Redington, A. L., Fang, X., Henne, S., Manning, A. J., Prinn, R. G., Dutton, G. S., Fraser, P. J., Ganesan, A. L., Hall, B. D., Harth, C. M., Kim, J., Kim, K.-R., Krummel, P. B., Lee, T., Li, S., Liang, Q., Lunt, M. F., Montzka, S. A., Mühle, J., O’Doherty, S., Park, M.-K., Reimann, S., Salameh, P. K., Simmonds, P., Tunnicliffe, R. L., Weiss, R. F., Yokouchi, Y., and Young, D.: Increase in CFC11 emissions from eastern China based on atmospheric observations, Nature, 569, 546-550, https://doi.org/10.1038/s41586019-1193-4, 2019.

Schulzweida, U.: CDO User Guide (Version 1.9.6), https://doi.org/10.5281/zenodo.2558193, 2019.

Solomon, S., Ivy, D. J., Kinnison, D., Mills, M. J., Neely III, R. R., and Schmidt, A.: Emergence of healing in the Antarctic ozone layer, Science, 353, 269-274, https://doi.org/10.1126/science.aae0061, 2016.

SPARC: SPARC Report on the Lifetimes of Stratospheric OzoneDepleting Substances, Their Replacements, and Related Species, edited by: Ko, M. K. W., Newman, P. A., Reimann, S., Strahan, S. E., SPARC Report No. 6, WCRP-15/2013, available at: https:// www.sparc-climate.org/publications/sparc-reports/ (last access: 12 November 2019), 2013.

Tiao, G., Reinsel, G., Xu, D., Pedrick, J., Zhu, X., Miller, A., DeLuisi, J., Mateer, C., and Wuebbles, D.: Effects of autocorrelation and temporal sampling schemes on estimates of trend and spatial correlation, J. Geophys. Res., 95, 20507-20517, https://doi.org/10.1029/JD095iD12p20507, 1990.

van Vuuren, D. P., Edmonds, J., Kainuma, M., Riahi, K., Thomson, A., Hibbard, K., Hurtt, G. C., Kram, T., Krey, V., Lamarque, J.-F., Masui, T., Meinshausen, M., Nakicenovic, N., Smith, S. J., and Rose, S. K.: The representative concentration pathways: an overview, Clim. Change, 109, 5-31, https://doi.org/10.1007/s10584-011-0148-z, 2011.

WMO (World Meteorological Organization): Scientific Assessment of Ozone Depletion: 2010, Global Ozone Research and Monitoring, Project-Report No. 52, 516 pp., Geneva, Switzerland, 2011. 
WMO (World Meteorological Organization): Scientific Assessment of Ozone Depletion: 2018, Global Ozone Research and Monitoring, Project-Report No. 58, 588 pp., Geneva, Switzerland, 2018. 